\title{
A INFLUÊNCIA DE UM PROGRAMA DE LEITURA NA TRANSFORMAÇÃO DAS CONDIÇÕES SOCIAIS DE APRENDIZAGEM NA ESCOLA
}

\author{
L'influence D 'Un Programme De Lecture Dans \\ La Tranformation Des Conditions Sociales \\ D’apprentissage Scolaire
}

\author{
Sílvia Roberta da Mota Rocha ${ }^{1}$ \\ Rita Vieira de Figueiredo ${ }^{2}$
}

\section{Resumo}

Este artigo analisa a transformação das condições sociais de apropriação da leitura de crianças em condições de exclusão escolar, as quais foram nomeadas como crianças remanescentes (CR). Trata-se de uma pesquisaintervenção realizada por meio de um programa que convocou leitores da comunidade (LC) para o ensino da leitura na escola. Os resultados do estudo evidenciaram o papel pedagógico do Programa na transformação das condições sociais de apropriação da leitura, cuja função social da escola, para estes alunos, contemplou a apropriação de estratégias socioafetivas e culturais que por sua vez atuaram como condição essencial para que o ensino se efetivasse, implicando na apropriação de estratégias cognitivas e metacognitivas. O programa permitiu, assim, alterar as relações sociais, familiares e, sobretudo, escolares, nas quais essas crianças se inserem, tendo provocado mudanças na relação destes sujeitos consigo, com os outros e com o saber, o que caracteriza a sua educação propriamente dita via escolarização. Palavras-chave: Apropriação da leitura; Exclusão escolar; Reprodução social.

\footnotetext{
1 Doutorado em Educação Brasileira pela Universidade Federal do Ceará; Doutorado sanduíche na Université Laval - Canadá; Professora da Universidade Federal de Campina Grande (PB). e-mail: roberta.rocha@uol.com.br

2 Pós-doutorado em Língua Escrita na Universidade de Barcelona; Doutorado (Ph.D.) em Psicopedagogia pela Université Laval - Canadá; Professora da Universidade Federal do Ceará. e-mail: rvieira@ufc.br
} 


\section{Resume}

Cet article présente les résultats d'une recherche-intervention portant sur l'apprentissage de la lecture chez des élèves d'un milieu défavorisé, à risque d'exclusion scolaire. Plus spécifiquement il analyse la transformation des conditions sociales d'apprentissage de la lecture chez ces élèves et de ses effets. Un programme élèves, a été appliqué par des volontaires issus de la même communauté que ces élèves. Les résultats indiquent que le programme, tel qu'appliqué, aurait exercé une influence positive sur les conditions sociales d'appropriation du langage écrit. Ce programme aurait aussi favorisé chez ces élèves le développement de nouvelles stratégies sur les plans affectif, social et culturel. Il s'agit de stratégies essentielles pour favoriser les apprentissages scolaires ainsi que les apprentissages métacognitifs et cognitifs. Des changements ont pu être observées notamment da ns les relations établies par ces élèves avec leur école et leur famille. Enfin, ces élèves auraient amélioré leur estime de soi ainsi que leur relation au savoir, ce qui semble avoir exercé un effet positif sur le maintien de la majorité d'entre eux dans l'école de leur communauté.de lecture qui faisait entre autres appel à l'élaboration de livres d'histoires par les

Mot clés: Apprentissage de la lecture; Exclusion scolaire ; Reproduction sociale.

O presente trabalho focaliza a transformação das condições sociais de apropriação da leitura por crianças em condições de exclusão escolar identificadas aqui como crianças remanescentes (CR), a partir de um Programa ${ }^{3}$ que convocou leitores da comunidade (LC) para participarem do ensino da leitura em uma escola pública da periferia da cidade de Campina GrandeParaíba. Analisa, especificamente, o papel pedagógico do Programa na apropriação de estratégias socioafetivas e culturais por estas crianças.

\section{O programa de leitura}

Neste trabalho, crianças remanescentes (CR) são alunos com experiências de insucesso escolar (também porque não decodificam o signo lingüístico), que têm idade cronológica igual ou superior a nove anos e escolaridade igual ou superior a dois anos. Adicionalmente, são alunos com comportamento turbulento ou dispersivo, alta distorção idade-série e algum grau e/ou tipo de deficiência, além de alvo de práticas marginalizadoras na

3 Intitulado Programa de Integração dos Leitores Remanescentes à Comunicação Letrada (PLDR). Maiores esclarecimentos sobre emergência e autoria do Programa, consultar Mota Rocha (2002). 
família e na escola. Esses alunos caracterizam-se como população destacável porque são considerados improdutivos para o sistema vigente.

Buscando intervir diretamente nas condições intra-escolares de apropriação da leitura por estas crianças, desenvolvemos uma investigação, cuja pertinência é reforçada por estudos que encorajam o desenvolvimento de pesquisas sobre o ensino da leitura como ato coletivo (SULLIVAN, 1988; FOUCAMBERT, 1994); estudos que analisam a interação criança, pais e leitura de histórias na escola, devido à relevante contribuição da mediação pedagógica realizada por usuários sociais da língua escrita (ANDERSON; TEALE, 1987; REGO, 1988; DAUDEN, 1994); e trabalhos que focalizam as concepções sociais dos educadores (escolares e familiares) sobre a leitura e o seu ensino (BEAUDOIN, 1997; LAVOIE, 2000).

Da perspectiva política, a pesquisa se baseia em estudos (SPÓSITO, 1989; DAMASCENO, 1998) que defendem que a luta pela democratização da educação deve ser travada em instituições públicas, a partir do estabelecimento de parcerias entre sociedade civil e instituições estatais, na tomada e execução de decisões, razão pela qual a comunidade atuou como um recurso humano para o ensino.

O estudo foi desenvolvido em uma escola pública de Campina Grande (PB) entre 1999 e 2001 e analisou 24 alunos remanescentes (CR) e 25 leitores da comunidade (LC) se utilizando de documentos escritos, questionários e entrevistas semi-estruturadas (com as CR, seus familiares e agentes escolares ${ }^{4}$ ), além de sessões de leitura, gravadas em vídeo.

As CR estavam numa faixa etária entre 7 e 14 anos, 18 eram do sexo masculino e 18 cursavam a segunda série do Ensino Fundamental. Suas famílias trabalhavam em setores informais da economia local e, em geral, no mínimo, um membro da família era alfabetizado. Os LC tinham empregos informais em setores menos remunerados do mercado de trabalho e estavam numa faixa etária de 11 a 50 anos, havendo predominância de adolescentes (18). Quatro LC eram alunos da escola, dez ex-alunos e outros dez, voluntários. ${ }^{5}$

O Programa consistiu na interação entre uma CR e um LC que, em duplas, deveriam realizar na escola três sessões semanais de leitura. Em cada sessão foram utilizados crachás dos leitores, livros contendo relatos reais de autoria dos CR, fichas de empréstimo dos livros, painéis com todo o texto da história em fichas, caixas com as letras do alfabeto em fichas, diários do leitor e fichas para contagem dos livros lidos.

\footnotetext{
Atores sociais da escola, docentes e demais funcionários, caracterizados como intermediários do sistema vinculados ao Estado, cujas representações sociais em interação com as condições objetivas da realidade resultam na escola como obra em construção (PENIN, 1989).

5 Um LC foi computado como informação desconhecida, em relação ao vínculo com a escola.
} 
As etapas de leitura eram as seguintes: 1) leitura do livro escolhido pela CR; 2) sinopse oral da história; 3) releitura do livro, apontando o texto escrito; 4) releitura do texto escrito no painel da história; 5) escrita de palavras e/ou sentenças na caixa de letras; e 6) registro da sessão no diário do leitor.

Nos dois primeiros meses de funcionamento do Programa, constatamos que as concepções dos LC sobre leitura e seu ensino eram pautadas na idéia de língua escrita como sistema de códigos, o que provocava a resistência das CR em participarem das sessões de leitura. Isso nos levou à implementação de um programa de formação para os LC, cujo objetivo era incrementar as suas condições de leitor, de mediador da leitura e de sujeito de direito à escola pública, apostando que este otimizaria a mediação pedagógica entre a dupla.

Outro problema enfrentado na pesquisa foi a inadequação entre o interesse das CR pelo enredo das histórias e os seus conhecimentos da língua escrita. O impasse foi solucionado com a produção discursiva das CR, que resultou na confecção de 44 livros (auto-relatos) para o Programa. Objetivamos valorizar a autoria destes indivíduos enquanto sujeitos de discurso e produzir um texto adequado aos conhecimentos de mundo e de língua das CR.

A confecção dos livros envolveu as seguintes etapas: 1) produção do relato oral; 2) transcrição do relato oral para o escrito, seguido da sua revisão, buscando a coesão e coerências textuais e a correção, sobretudo, da concordância verbonominal; 3) leitura do relato escrito revisado para o autor objetivando a sua concordância, ajuste e/ou autorização; 4) escolha de título e ilustrador; 4) edição do relato em formato iódice, preservando as identidades dos sujeitos por meio de pseudônimos; e 5) catalogação dos livros na biblioteca.

Os relatos expressam grande compreensão da realidade social, a exemplo da cadeia de violência a que as CR e suas famílias são submetidas. Ressaltam a figura paterna como um sujeito ausente e/ou principal agente da violência física/verbal que sofrem, a conivência da sociedade com a exploração do trabalho infantil, a avó como figura que exerce o papel de autoridade familiar, a experiência rural destas crianças com fazendas e animais domésticos como potencial de trabalho que estas familias têm e a surpreendente reação das CR que - além de alvo - transformam-se em agentes de resistência - denunciando pais, ou cuidando da mãe, em vez de serem cuidadas. Também observamos a ironia ou o espírito de vingança para com a polícia, compreendida como adversário no lugar de autoridade protetora da sociedade civil.

\section{o papel pedagógico do programa: apropriação de estratégias de inserção escolar}

A dimensão do significado da apropriação da leitura como estratégia de inserção escolar nas vivências social e escolar destas crianças 
é melhor compreendida quando conhecemos como vivem estas crianças em casa e na escola.

Dezessete CR habitam em residência própria, embora sejam casas tipicamente construídas de taipa e/ou tijolo, algumas delas com banheiro e muitas sem esgoto. Doze CR moram com os pais (casal), cinco vivem com apenas um dos pais e outros seis com os avós. ${ }^{6}$ Cinco CR têm experiência com o trabalho infantil e sete apresentam uma relação direta com o meio criminal, sendo, portanto, indivíduos em situação de risco social. Nesse caso, a remanescência é um problema social que envolve aspectos socioafetivos vivenciados no ambiente familiar, sendo, em muitos casos, acentuada no meio escolar.

$\mathrm{Na}$ escola, estas crianças têm como características predominantes o estabelecimento de vínculos negativos com a instituição e com o conhecimento e, em decorrência, a afirmação, nas relações sociais, pela exclusão do saberobjeto (CHARLOT, 2000). ${ }^{7}$ Apresentam dificuldades de apropriação das estratégias socioafetivas, aspecto também observado por Saint-Laurent et al. (1995) e os seus principais desafios educacionais são inserirem-se na lógica escolar do conhecimento, predispondo-se a participar e a lidar com a condição bumana de errantes.

A participação dos alunos no Programa permitiu não somente que eles desenvolvessem estratégias de leitura, mas que se apropriassem de vários conhecimentos que podem ser considerados como estratégias de inserção escolar, já que se constituíam instrumentos que lhes ajudavam a lidar melhor com a sua condição de remanescente, nos contextos escolar e familiar. Os diversos tipos de estratégias originárias desses conhecimentos foram identificados como (meta) cognitivos, sociais, culturais e afetivos.

O papel pedagógico do Programa permitiu a melhor inserção escolar dos alunos remanescentes a partir da apropriação de tais estratégias, impulsionada pela relação entre (meta) cognição e socioafetividade. Entretanto, por uma questão de limite de espaço, não abordaremos neste trabalho as estratégias (meta) cognitivas. As estratégias sociais e afetivas serão tratadas numa mesma sessão e as culturais numa sessão distinta. Essas estratégias foram definidas por nós como sendo relações interpessoais do indivíduo num grupo social, tais como as habilidades de se expressar, de negociar pontos de vista antagônicos, de resolver problemas pelo diálogo, de aceitar decisões coletivas, de internalizar normas sociais e de lidar com os limites da convivência social. Os indícios da presença delas foram identificados como sendo o comportamento

6 Um LC foi computado como informação desconbecida.

7 O saber-objeto é aquele no qual o aprender significa tomar posse de conteúdos intelectuais com a ajuda de mediadores experientes; expressa-se por meio da linguagem escrita; implica o eu reflexivo do indivíduo e constitui um produto autônomo.

Diálogo Educ., Curitiba, v. 7, n. 22, p. 245-258, set./dez. 2007 
da criança em casa pela aceitação/questionamento de normas familiares e pelo comprometimento com a melhoria de sua vida/escolarização; e as formas de participação da criança na escola pela aceitação/questionamento de normas escolares, pelo interesse e assiduidade em atividades de leitura e pela construção de vínculos positivos com a escola, o conhecimento e os sujeitos.

As estratégias culturais referem-se aos indícios de construção do estatuto do leitor por meio da apropriação dos usos e funções da escrita e do motivo social da aprendizagem da leitura; da construção de vínculos positivos e espontâneos com a língua escrita e da postura de dessacralização ${ }^{8}$ da informação escrita (FOUCAMBERT, 1994).

Indicios da presença da estratégia: os usos e funções da língua escrita em práticas sociais de letramento, apropriação do motivo social da aprendizagem da leitura, o posicionamento sobre o enredo lido e atitudes reivindicativas. As estratégias afetivas referem-se aos ganhos de auto-estima e de autoconfiança.? Foi considerado um indício da presença da estratégia a disposição da criança em participar do grupo e em se relacionar com a professora, a aceitação da sua condição de errante, indícios de melhoria do asseio e vaidade pessoais e construção/consolidação de relações socioafetivas.

A análise da estratégia socioafetiva tomou como referência o comportamento do aluno em casa, as diferentes formas de participação na escola e os ganhos de autoconfiança. Os resultados indicaram que houve mudança no comportamento dos alunos em casa e na escola no que se refere à aceitação de normas de convivência; e, sobretudo, no próprio comprometimento com a melhoria de sua qualidade de vida/escolarização, conforme ilustra o diálogo abaixo entre o avô dos alunos André e Arnaldo e a pesquisadora:

Avô - Eles disseram: Vô, é pro senhor ir assistir a uma reunião amanhã!! Aí eu digo: E se for pra negócio mal feito, não? Ele disse: não, pode ir sem cisma, que num é negócio mal feito não!

Pesquisadora - O senhor vê eles lendo uns livrinhos?

Avô - Vejo com os livrinhos, lendo. De vez em quando eles estão lendo, um pro outro, porque Josefa (sua esposa) num deixa eles saírem de qualidade nenbuma, ai eles sentam numa cadeira, outro noutra, e eles teimando um com o outro: É assim, assim... O outro diz: Ah é assim...

Pesquisadora - Eles lêem juntos? Eles lêem só ou tem alguém lendo com eles?

\footnotetext{
8 Habilidades do sujeito de posicionar-se com criticidade e de ler nas entrelinhas do texto (o que o autor se esforçou por não explicitar no texto, mas que se encontra interdito).

9 A auto-estima se refere à relação do sujeito consigo mesmo, enquanto a autoconfiança diz respeito à relação do sujeito com o mundo, a partir da auto-estima.
} 
Avô - Junto, sim. É eles sozinbo!

Pesquisadora - E o que o senhor tá achando da leitura deles?

Avô - Tá melhorando 100\%.

Pesquisadora - E por que o senhor diz isso?

Avô - Porque eles tão lendo qualquer coisa, sabe como é? Aí eu tô gostando.

Pesquisadora - E o comportamento em casa, como é que tá?

Avô - Melhorou 100\%.

Pesquisadora - Como era antes, seu Jonas?

Avô - Saíam, chegavam em casa dez, onze horas da noite. Era preciso botar gente do vizinho pra ver se pescava eles!

Pesquisadora - E agora?

Avô - Agora eles tão chegando cedo. Quando dá sete, oito horas já tão tomando banho, sentam lá na cadeira de novo, aípega o livrinbo e vai lê.

$\mathrm{Na}$ escola também foram observadas mudanças importantes no comportamento desses alunos conforme relata a professora de educação física:

[...] eu acho que tem algumas regras que eles estão interiorizando mais, que eu creio que tem a ver em alguns momentos com relação à leitura. Por exemplo, no caso de Arnaldo e André. Eu acho que o fato de ter alguém assim que lê com eles, de alguma forma enche a bola deles, no sentido de na escola. E pelo menos quando eu digo "André não faça isso[...]" Não que ele não faça isso em todos os momentos, mas ele já não responde assim, já não tem mais aquele tipo de resposta, assim, de desacatar, de fazer tromba, entendeu? Eu sinto que ele já aceita que têm coisas que ele não pode fazer. Eu não sei se isso é fruto do Projeto (referindo-se ao PLDR) mas, assim, eu tô vendo que tá havendo essa mudança, da auto-estima. Eu tô sentindo eles um pouco menos avessos à ordem porque, por exemplo, André mesmo, você dizer "faça assim, não pode fazer isso [..].”, ele já ficava com a tromba, não aceitava muito essa coisa de ter regras.

No que se refere às formas de participação na escola, identificamos a apropriação, de regras de convivência com o emprego de expressões como bom dia, obrigado, por favor. A aceitação destas normas de sociabilidade pelas CR ganha realce se considerarmos as suas dificuldades de assimilação das estratégias sociais. No início da pesquisa, o comportamento desses alunos era considerado inapropriado para o ambiente escolar, como ilustram os relatos abaixo: 
Quando o pessoal falou: tu vai ler com quem? Eu falei: com André. Ah, eu não acredito não! Menina, tu vai quebrar a cabeça, ele é muito danado! Num gosta de ir, diz que deixou a bolsa em casa, mas foi de propósito. Não quer ir, ele vai no dia que quer, no dia que num quer, não vai. E é danado, não pára quieto! Fica se levantando, nunca faz o que você pede. Faz o que ele quer (Amélia nos relatando a reação dos agentes da escola e dos LC em relação a sua escolha de ler com André - CR).

Registramos também ganhos relativos ao interesse das CR nas atividades de leitura pertinentes ao Programa e, em menor proporção, no seio familiar; bem como à consolidação e/ou ao estabelecimento de vínculos positivos com a instituição, indícios da predisposição das CR para estabelecerem vínculos positivos com o conhecimento e a comunidade escolar.

Tal predisposição pode ser atestada pela assiduidade das CR no Programa: a média de sessões realizadas em seis meses de funcionamento do Programa foi de 32,4 sessões por dupla. Mais ainda, consideramos as atitudes demonstrativas da assiduidade interessada, isto é, aquelas que indicavam a presença da CR na escola com a disposição para a aprendizagem ou para o engajamento com o saber ler na escola, como vemos a seguir:

Eu vou aprender a ler que épra eu ler com os outros meninos da escola! (José, $\mathrm{CR}$, falando para a pesquisadora).

O crescimento da autoconfiança destas crianças foi observado por meio de atitudes que indicavam a disposição delas em se relacionarem com as professoras; e de atitudes de mostrar tarefas, tentar resolver problemas/exercícios, solicitar/aceitar/conferir ajuda, reconhecer as suas limitações enquanto seres humanos. O trecho abaixo é ilustrativo desse aspecto:

Eu via que ele era muito tímido e parece que tinha medo de chegar junto a mim e perguntar. Tinha medo de errar, eu acredito. Eu acho que era medo de eu dizer que tava errado. Dizer: "não, não é assim". Eu dizia: "olhe, não tenha medo. Faça o que você sabe, o que você consegue. Quando você não souber, eu venho lhe ajudar". Ele, agora, tá perdendo esse medo. Eu acho que ele tá se libertando disso. Tá seguro! (Maura, sobre o avanço de Wesley).

A melhoria da autoconfiança ainda foi evidenciada pela construção de vínculos socioafetivos (amizade) da CR com as pessoas do Programa e da escola, conforme depoimento abaixo: 
Professora - Ele se sente assim, eu acho que, importante quando vai ler. Não sei se é a leitora (referindo-se à LC da CR) também, num sabe? Ela tem muito manejo com ele e também é uma pessoa mais velha, respeita às vezes, a vontade dele. Acho que ele tá se sentindo cidadão, que ele não era. Tá começando a se sentir gente! Às vezes, no início, sumia um objeto ou outro, ai ele, por si só, me revelava. Dizia: "olhe que eu encontrei na minha bolsa". Mas eu, sabendo que era ele, né, eu não dizia "olhe quem tirou me devolva", porque os demais olhavam pra ele, ai ele por si só já se [...]. Hoje não acontece isso, pelo menos não é ele.

Pesquisadora - Por que é que você diz que ele tá se sentindo cidadão? Professora - Porque tem uma escola, porque tem alguém que olha para ele, que senta junto, que tem colegas tá se sentindo gente, que tá participando, dando opiniôes, sabe, que reivindica também. Ele diz: "eu num tô gostando disso, por que é assim?" Não é tão reprimido como era!

Como o saber se constrói numa relação identitária com os outros, na medida em que o saber só existe com a permissão do sujeito que aprende (CHARLOT, 2000), a construção destes vínculos é considerada uma importante estratégia social.

A apropriação das estratégias culturais pelas CR diz respeito à construção dos usos e funções sociais da escrita no contexto letrado e à assimilação do motivo social da aprendizagem da leitura, sugerindo-nos a possibilidade de construção de uma relação social, positiva e espontânea com a língua escrita em contextos reais de comunicação - nas atividades sociais -, como um indício de construção do estatuto do leitor, como vemos no diálogo entre a avó (A) e o avô (O) de uma CR e a pesquisadora (Pe):

A - [... é épra vim de tarde, do que pela manhã!

Pe - Por quê?

A - Ela diz que é por causa da leitura, que ela gosta.

Pe - Ela tá falando de Edilene (uma CR).

O - Quando ele tiver aqui, a senhora pode dá uma dica a eles, "vocês se interessem todos os dias, que seu avô vai comprar pra cada um uma bicicleta".

Pe - Oh meu Deus! Pois seu Jonas, tá já chegando o dia porque André já tá lendo e Arnaldo tá já já!

A - É muito importante a pessoa saber ler [...]. 
O depoimento que se segue testemunha a assimilação do motivo social da aprendizagem da leitura e da valorização dela como atividade social:

CR - [...] porque quando a pessoa se formar aí não precisa colocar o dedão e pode assinar, nê? (trecho retirado de uma reunião de pais com o PLDR, na qual Edilene estava presente com a sua avó responsável).

Pe - Como é que ele (referindo-se a CR) está, depois de participar deste Programa?

Mãe - Depois ele melhorou mais, sempre qualquer coisa que ele pega ele tá lendo, qualquer coisa que passa na televisão ele lê, ele aprendeu muito! (Mãe de Alexandre, uma CR).

$\mathrm{Pe}-$ Como é que ele faz com esse livro quando ele chega em casa?

Mãe - Chega em casa, eu peço pra ele lê um pouquinho pra mim, ele lêpra eu ouvir.

$\mathrm{Pe}-L \hat{e}$ ?

Mãe - Lê, sai pra rua mais o pai, quando sai daqui da escola né. Ele lê bastante, as numerações das casas, tudinho ele lê. Ai quando chega em casa ele me conta: "Mãe eu li..." Aí o pai diz: "Só acredito se você disser o que leu lá!"Ai ele vai e diz tudinho, decora na cabeça e chega em casa e diz" (mãe de Neto, CR).

Sabemos que a atividade social é o locus de ação e de formação de leitor em condições sociais de apropriação da leitura. Nela, o mediador se coloca como usuário da língua, em contraposição ao ensino artificializado, além de negociar o motivo da aprendizagem da leitura, como está ilustrado abaixo:

[...] eu falo sempre assim: "olhe, você lê em casa e se você ler bem aqui, você continua lendo bem, eu falo com Roberta pra fazer o teste, pra você ir pros Quase-independente (referindo-se a uma categoria superior de leitores em outro programa de leitura da escola), pra você aprender mesmo, pra você lê igual a gente! Eu quero ler com outras pessoas", eles dizem! (Isabela, LC e coordenadora de comitê, ex-aluna da escola e irmã de uma CR).

Talvez por isso, tenhamos registrado o interesse das CR em participar do Programa como leitores para outras crianças, enquanto membros de uma comunidade leitora:

Eu vou aprender a ler que épra eu ler com os outros meninos da escola! (José, $\mathrm{CR}$, dizendo à pesquisadora). 
Assim, verificamos que a aprendizagem da leitura, para as CR, parece ter estado atrelada ao distanciamento do estigma social de analfabeto e à possibilidade de inserção da comunidade letrada, cuja uma de suas regras é a condição de leitor-alfabetizado que media a aprendizagem da leitura para leitores iniciantes.

A presença de atitudes reivindicativas, como uma das características do leitor e indício de apropriação destas estratégias, foi um outro aspecto observado:

Quando eu peguei Edilene, toda vez que eu, às vezes chegava tarde, ela tava esperando [...] "Ah, tô esperando aqui e tu custa, num sei quê" (referindo-se às reclamações da CR)[...] mesmo assim, sabe, me dando bronca. Aí eu: "me desculpe, por deixar você esperar." [...] Eu repito só uma vez (referindo-se à leitura do livro), aí eu pergunto a ela: "você quer ler de novo", pra ver se ela consegue saber essa palavra. Aí ela diz: "quero!"Aí continua! (Fabrício, LC de Edilene).

Nesse caso, a criança assujeitada passa a ser tratada com respeito pelo seu LC, sendo ressaltada a sua condição de indivíduo. A sua condição de criança pobre e de risco social parece não interferir, negativamente, no tipo de relação construída pela dupla leitora. Esta é a transformação da relação pedagógica elementar nas condições sociais de apropriação da leitura, qual seja, aquela que enxerga nas camadas trabalhadoras o direito de aprender com respeito à sua dignidade. Tal reconstrução também foi otimizada pela condição de autoria das CR, permitida pela produção dos livros, tendo permitido outro lugar para essas crianças na escola: o lugar de sujeitos de discurso.

\section{Apropriação da leitura e reprodução social na escola}

A análise da apropriação das estratégias acima descritas indica melhorias no comportamento dos alunos em casa e na escola, na autoconfiança, na apropriação do motivo social da aprendizagem da leitura e na construção de atitudes reivindicativas.

Tal apropriação ocorreu impulsionada pela relação estabelecida entre cognição e socioafetividade das CR, construída na mediação pedagógica entre a dupla leitora; e pelos componentes da intervenção: a transposição, para a escola, da atividade social de leitura compartilhada de histórias, a potencialização das condições de participação e de acerto das CR e a análise da língua escrita no texto e na atividade.

O conceito de assiduidade interessada, como uma evidência do início da quebra da afirmação da CR pela exclusão do conhecimento e, 
conseqüentemente, do começo da sua disponibilidade para estabelecer vínculos positivos com o conhecimento e a escola parece indicar que houve melhorias significativas nas condições sociais de apropriação da leitura pelas CR, a partir de sua participação no programa em análise.

Os dados sugerem, ainda, que a função social da escola, para estes alunos, deve se ampliar para contemplar a sua educação, a partir da construção de relações sociais de respeito entre eles e os demais membros da escola. Estas relações catalisam a apropriação de estratégias socioafetivas pela CR, que passa a atuar como condição para que o ensino se efetive, facilitando a apropriação de estratégias (meta)cognitivas, a exemplo dos avanços das CR na construção do sentido, na decodificação do signo lingüístico e na compreensão da representação escrita.

Em síntese, na relação entre cognição e socioafetividade, a pesquisa evidenciou que, ao reconhecer a CR enquanto sujeito de direito, o LC estabelece uma relação de ensino pautada no respeito e no comprometimento com a melhoria de sua condição de sujeito, e não apenas de aluno, o que significa o comprometimento com a sua condição de vida. Esse comprometimento do LC, por sua vez, mobiliza a CR para engajar-se com o saber, rompendo com a sua afirmação na escola pela exclusão do saber-objeto (leitura). Essa reconstrução socioafetiva da CR enquanto sujeito permite-lhe atuar no campo cognitivo, provocando a assiduidade interessada, e otimizando avanços nas dimensões individual e social do letramento (SOARES, 1999).

De modo oposto, quando começa a afirmar-se no campo do saber, enquanto sujeito que pode e está aprendendo a ler, esse estatuto do leitor desnaturaliza a produção do insucesso escolar e consolida o seu lugar de sujeito competente, permitindo-lhe, cada vez mais, avançar na sua reconstrução socioafetiva.

No entanto, estes ganhos devem ser pensados no contexto da deseducação, que expressa a relação contraditória entre família e escola sobre a sua função social. Ou seja, quando os agentes da escola e da comunidade apresentavam expectativas e atitudes antagônicas diante do desempenho escolar das CR, a despeito dos ganhos que elas vinham obtendo e do discurso social pela inserção das nossas crianças na escola como antídoto contra a violência social e instância privilegiada para a formação de leitores (ZALUAR; LEAL, 2001).

Práticas escolares de distanciamento da criança da escola, relações baseadas na violência verbal, empecilhos para a utilização da biblioteca e pressão sobre o desempenho escolar da criança na escola são algumas evidências deste movimento contraditório entre o discurso defendido pela sociedade e as práticas pedagógicas escolares com repercussões negativas no desempenho escolar das CR. 
Assim, na relação entre comunidade, escola e letramento, situações como essas são indicadores da interferência de aspectos político-institucionais na apropriação de estratégias pela $\mathrm{CR}$ e da necessidade de construção de parâmetros conceituais mínimos entre escola e comunidade a serem incorporados no projeto político-pedagógico da escola, evitando, com isso, que os alunos sejam sacrificados, além de impulsionar a coerência entre discurso social e práticas escolares.

Finalmente, a reconstrução das CR como sujeitos leitores se deu por meio da apropriação de diversas estratégias de inserção escolar, revelandonos a subversão do lugar social de assujeitamento que lhes é atribuído, historicamente, e atestando a desnaturalização da produção do atraso na escola, importante aspecto que explicita o caráter ideológico da reprodução social na escola pública.

Ao estreitar a relação entre pobreza, competência e letramento, as conquistas das CR neste campo colaboram com a desconstrução do estigma de sujeitos incapazes, ao mesmo tempo em que permitem a problematização das deterioradas condições escolares de acesso, produção e distribuição do conhecimento, na escola pública, para os membros das camadas trabalhadoras, o que fragiliza a disseminação da ideologia burguesa no campo educacional.

Em síntese, a conquista do lugar de direito e de leitor pelas CR por meio do letramento evidenciou o papel pedagógico do Programa na transformação das condições sociais de apropriação da leitura e da escrita na escola, uma das importantes causas intra-escolares da produção do atraso. Tal transformação permitiu alterar as relações sociais familiares e, sobretudo, escolares, nas quais as CR se inserem, tendo provocado mudanças significativas na relação destes sujeitos consigo, com os outros e com o saber, o que caracteriza a sua educação propriamente dita via escolarização formal.

\section{Referências}

ANDERSON, A. B.; TEALE, W. H. A lectoescrita como prática cultural. In: EMILI, Ferreiro; ALÁCIO, Margarita G. Os processos da leitura e escrita: Novas Perspectivas. Porto Alegre: Artes Médicas, 1987.

BEAUDOIN, I. Les interactions enseignante-élèves lors de la lecture d'histoire en première année. Mémoire présenté à la Faculté des études supérieures de l'Université Laval pour l'obtention du grade de maître ès arts (M. A.). Département de didactique, pysichopédagogie et technologie éducative. Programme de maîtrise en pyschopédagogie (adaptation scolaire). Faculté des Sciences de l'Ëducation. Université Laval: 1997. 
CHARLOT, B. Da relação com o saber: elementos para uma teoria. Tradução de Bruno Magne. Porto Alegre: Artes Médicas, 2000.

DAMASCENO, M. N. Tecendo a democracia na escola: outro olhar sobre a participação popular na prática pedagógica. Educação em Debate, v. 20, n. 36, 1998.

DAUDEN, A. T. B de C. A criança e o outro na construção da linguagem escrita. São Paulo: Pancast, 1994.

FOUCAMBERT, J. A. Leitura em questão. Porto Alegre: Artes Médicas, 1994.

LAVOIE, N. Les Parents et L'Apprentissage de L'Écriture. Thèse présentée à la Faculté des études supérieures de l'Université Laval pour l'obtention du grade de Philosophiae Doctor (Ph. D.). Département d'études sur l'enseignement et l'apprentissage. Faculté des Sciences de l'Éducation. Université Laval: Québec, 2000.

MOTA ROCHA, S. R. da. Leitores da comunidade e crianças lêem histórias na escola: Programa de integração da criança remanescente à comunicação letrada. 2002. Tese (Doutorado em Educação Brasileira) - Universidade Federal do Ceará, Fortaleza, 2002.

PENIN, S. Cotidiano e escola: a obra em construção. São Paulo: Cortez, 1989.

REGO, L. L. B. Literatura infantil: uma nova perspectiva da alfabetização na pré-escola. São Paulo: FTD, 1988.

SAINT-LAURENT, L. et al. Programme d'intervention auprès des élèves à risque: une nouvelle option éducative. Montréal, Canadá: Gaetan Morin, 1995.

SPÓSITO, M. P. Redefinindo a participação popular na escola. In: Cadernos do CEDI, n. 19, 1989.

SOARES, M. Letramento: um tema em três gêneros. Belo Horizonte: Autêntica, 1999.

SUlLIVAN, M. Parents and schools. London: Scholastic, 1988.

ZALUAR, A.; LEAL, M. C. Educação: meio de erradicação da pobreza ou antídoto à violência? In: D'INCAO, M. A. (Org.). O Brasil não é mais aquele: mudanças sociais após a redemocratização. São Paulo: Cortez, 2001. 